The compound $\mathrm{AuHg}_{4}$ decomposes into $\mathrm{Atr}_{2} \mathrm{Hg}_{5}$ and $\mathrm{Hg}$ at its melting point.

Photomicrographs were made of the entectics and compounds both as cooled in air and quenched just below the freezing point. Because of difficulty of reproduction these are not published.

The authors wish to express their gratitude to Dr. G. McP. Snitl for the original conception of the problem and also the method of attack.

URBANA, ILLINOIS.

[CONTRIBUTION FRON THE WALKER LABORATORY, RENSSELAER POLYTHCHNIC INSTITUTE.]

\title{
NITROSO R-SALT, A NEW REAGENT FOR THE DETECTION OF COBALT.
}

BX H. S. VAN KLOOSTER.

Received January 18, 1921.

As is well known, 'Tschugaeff's reagent dimethylglyoxime affords an extremely sensitive means of detecting nickel even in the presence of large quantities of cobalt. Experiments show that one part of nickel in $f(1)(1,-$ 000 parts of water still gives a red coloration, and it is possible to detect nickel in the presence of 5,000 times its weight of cobalt.

It is interesting to note that an oxime of the naphthalene series affords an easy and sensitive means for the detection of cobalt in the presence of an excess of nickel and that it can also be applied when other metals are present in the solution.

Although a number of related compounds have been described in the literature, this oxime itself has not been described.

Hoffmann ${ }^{1}$ mentions the preparation of the nitroso compound of Schaeffer's salt (sodium 2,6- $\beta$-naphtholsulfonate) which yields with ferrous salts green, and with cobalt salts brownish-red dyes. The iron dye is known as naphthol green $\mathrm{B}$ and its formula is given as $\left(\mathrm{C}_{10} \mathrm{H}_{5} \mathrm{NO}_{5} \mathrm{SNa}\right)_{2} \mathrm{Fe}$." Knecht ${ }^{3}$ finds that cobalt salts form brown coloring matters while nickel salts produce yellow colors.

By treating $\mathrm{R}$-salt (sodium 2,3,6- $\beta$-naphtholdisulionate) with nitrous acid a similar nitroso derivative is formed to which the following structure must be ascribed.

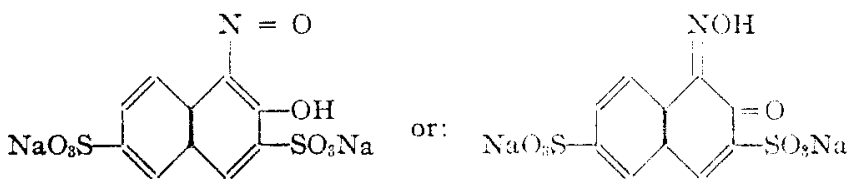

Calc, $\mathrm{Na}:$ 12.20. Found: $11.96,11.63$.

: Hoffmann, Ber., I8, 46 (1885).

"Green, "Organic coloring matters," J.ondon, 1908, p. 170.

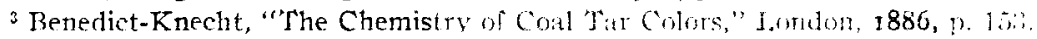


On a small scale this nitroso-R-salt may be prepared as follows.

$35 \mathrm{~g}$. of pure R-salt ( $1 / 10$ mole) is dissolved in $400 \mathrm{cc}$. of water and the solution acidified with $10 \mathrm{cc}$. of conc. hydrochloric acid (sp. gr. 1.19). 'The liquid is cooled to $8^{\circ}$ to $10^{\circ}$ and kept in motion by means of a stirrer, while a cold solution of $7.2 \mathrm{~g}$. of sodium nitrite in $20 \mathrm{cc}$. of water is run in drop by drop in the course of half an hour. After a while an orangevellow precipitate begins to form. When all the nitrite has been added the stirring is continued for some time. The precipitate which forms a rather thick paste is filtered with suction on a porcelain funnel, and the resulting cake, which is still slightly orange in color, changed into a thin paste with a little cold water. It is then again, filtered with suction, washed with some cold water and finally with alcohol. Yield, about $80 \%$.

The compound has a golden-yellow color and crystallizes from aqueous solutions in fan-shaped crystals. It is fairly solubie in hot water In cold water it is slightly soluble ( 100 parts of water dissolve $2.6 \mathrm{~g}$. at. $\left.18^{\circ}\right)$ and still less in methyl and ethyl alcohol. In the dry state the salt is very stable and can be kept indefinitely when not exposed to the direct sunlight. The same can be said of its solution in water which does not change when kept in stoppered bottles for a year or longer. ${ }^{1}$

Like the corresponding nitroso compound of Schaefier's salt, nitroso-Rsalt forms a green colored substance with ferrous salts. Nickel salts give a brownish-yellow color. Cobalt salts form a beautiful red dye which, on account of its exceedingly stable character and its close analogy with the cobalt compound of $\alpha$-nitroso- $\beta$-naphthol, must have the formula $\left(\mathrm{C}_{10} \mathrm{H}_{5} \mathrm{NO}_{8} \mathrm{~S}_{2} \mathrm{Na}_{2}\right)_{3} \mathrm{Co}$. Attempts to obtain well-defined crystals in order to check this formula by direct analysis failed, however. In the solid state the dye forms shining black flakes or a reddish powder which dissolves in water, methyl and ethyl alcohol with a deep red color. Wool and silk are dyed a clear red from an acid bath. The color is very stable and is not destroyed by heating with acids.

A solution of $0.5 \mathrm{~g}$. of nitroso-R-salt in $100 \mathrm{cc}$. of water is a very sensitive indicator for the detection of cobalt in solution. The presence of rickel and other metals which form colored ions affect the sensitiveness if the reaction but by conforming to the following directions the cobalt can be readily detected in the presence of 200 times its weight of nickel.

To $2 \mathrm{cc}$. of a dilute solution (containing from 1.5 to $2 \mathrm{~g}$. of anhydrous salt in $100 \mathrm{cc}$. of water) of the material to be tested is added about one $\mathrm{g}$. of powdered sodium acetate and then $2 \mathrm{cc}$. of the nitroso-R-salt solution. The liquid is heated to boiling over a small flame and after the gradual addition of about $1 \mathrm{cc}$. of conc. nitric acid (sp. gr. 1.4) the boiling is con-

'A brief reference to nitroso-R-salt was later found in Möhlau and Bucherer's "Farbenchemisches Prakticum," Berlin, I920, p. 140. 
tinued for at least one minute. A permanent change in color towards red will reveal the presence of cobalt. The colors produced by iron, nickel, copper and other metal salts are destroyed by the acid while the cobalt color persists. It was found that the presence of acid in the unknown solution has a retarding effect on the production of the cobalt color. ${ }^{2}$ Hence it is necessary when the acid has not been previously removed by evaporating to dryness to neutralize the excess of acid by adding sodium acetate before the liquid is tested.

Experiments carried out with varying amounts of metals which give colorless ions in solution (silver, lead, cadmium and others) showed that their presence does not interfere with the test. Salts of nickel, chromium, iron and copper, however, mask the color of the cobalt compound when the salt concentration is greater than $0.1 \mathrm{M}$ and only little cobalt is in solution. By limiting, therefore, the concentration of the dry salt to 1.5 to $2 \mathrm{~g}$. per $100 \mathrm{cc}$. of solution it is possible to detect cobalt provided the solution contains not less than $0.03 \mathrm{mg}$. of cobalt per cc. Since the reaction is based entirely on the color produced only a very rough estimate of the amount of cobalt present can be made.

Experiments were carried out, following the procedure outlined above, using $\alpha$-nitroso- $\beta$-naphthol instead of nitroso-R-salt. This reagent, (which was first recommended as a precipitant for cobalt in the presence of nickel salts by Ilinsky and Knorre) ${ }^{2}$ is almost insoluble in cold water. It is used in the form of a dark brown solution made up by dissolving 8 $\mathrm{g}$. in $300 \mathrm{cc}$. of cold glacial acetic acid and diluting with an equal volume of water. Apart from the fact that this solution does not keep well and has to be made fresh each month, it was found that on adding 2 cc. of this solution to a solution which was free from cobalt, copper, chromium and iron a small amount of a dark precipitate of nitroso-naphthol is formed which is not dissolved by subsequently boiling the liquid with nitric acid. Although the precipitates obtained with copper, chromium, and iron dissolve by boiling with nitric acid while the cobalt compound

1 It may be remarked that this is an excellent example of negative catalysis which is well worth showing in the lecture. Fifty cc. of a slightly colored cobalt solution (about $0.01 M$ ) is placed in each of 4 beakers. To the second, third and fourth beaker different amounts of hydrochloric acid (sp. gr. 1.19), say $0.5,3$ and 10 cc., are added. Beginning with the most acid solution about $10 \mathrm{cc}$. of nitroso-R-salt solution is poured into each of the 4 beakers. A red color is produced at once in the first beaker while the reaction in the other beakers is not completed until after several minutes or hours, depending on the hydrogen-ion concentration in these acid solutions. Addition of acid to the beaker in which the color appeared first does not destroy the red color while addition of a sufficient amount of sodium acetate (either in the form of a powder, or as a concentrated solution in water) immediately produces the red color in any of the other beakers.

2 Ilinsky and Knorre, Ber., I8, 699, 2728 (1885). See also Chapin, This Journal, 29, 1029 (1907). 
$\left(\mathrm{C}_{10} \mathrm{H}_{6} \mathrm{NO}_{2}\right)_{3} \mathrm{Co}$ is not (or only slightly) attacked, the presence of small quantities of cobalt may escape detection (due to the fact that there is present a dark residue derived from the precipitated nitroso-naphthol) unless a confirmatory test by means of the borax bead is made. The use of nitroso-R-salt in the same conditions does not require an additional bead test. In the regular course of qualitative analysis the test with nitroso-R-salt can be applied to the residue of dry chlorides, or after separating the nickel, as a confirmatory test for cobalt. ${ }^{1}$ The compound is rather expensive, ${ }^{2}$ but considering the large number of determinations that can be made with a small quantity of material it is more economical to use than other reagents which are in use for the qualitative determination of cobalt.

Troy, N. Y.

\section{SOLUTIONS OF METALS IN NON-METALLIC SOLVENTS. VI. THE CONDUCTANCE OF THE ALKALI METALS IN LIQUID AMMONIA. ${ }^{3}$}

By Charles A. Kraus.

Received January 19, 1921.

\section{Introduction.}

In the fifth paper of this series it was shown that, for a given concentration interval, the electromotive force of a concentration cell, in which sodium is employed as electrolyte in liquid ammonia between platinum electrodes, decreases rapidly at higher concentrations and apparently approaches a value of zero in very concentrated solutions. From the results of the fourth paper of this series it follows that, in solutions of sodium in ammonia, we have present normal sodium ions and a negative ion which appears to be characteristic of solutions of all metals in ammonia. If the electrode processes in the case of these concentration cells are reversible, and many facts indicate that this is the case, then the relative speeds of the positive and negative carriers may be calculated approximately, assuming the laws of dilute solutions to hold true. While these laws do not hold precisely, it may, nevertheless, be expected that the results of calculations based upon this assumption will be correct as to the order of magnitude.

The results indicate that, as the concentration of the sodium solution increases, the relative speed of the negative carrier increases. This increase is at first relatively slow, but, at the higher concentrations, the

"Noyes, "Qualitative Chemical Analysis," Procedures 68 and 70.

:Obtainable from Eimer and Amend.

"Previous papers of this series have appeared as follows: I, This Journal, 29, 1557 (1907); II, ibid., 30, 653 (1908); III, ibid., 30, 1157 (1908); IV, ibid., 30, 1323 (1908); V, ibid., 36, 864 (1914); Trans. Am. Electrochem. Soc., 2 T, 119 (1912). 